Article

\title{
Green Tax Reform in Australia in the Presence of Improved Environment-Induced Productivity Gain: Does It Offer Sustainable Recovery from a Post-COVID-19 Recession?
}

\author{
Maruf Rahman Maxim * and Kerstin K. Zander \\ Northern Institute, Charles Darwin University, Casuarina, NT 0810, Australia; kerstin.zander@cdu.edu.au \\ * Correspondence: marufrahman.maxim@cdu.edu.au
}

Received: 6 July 2020; Accepted: 10 August 2020; Published: 12 August 2020

\begin{abstract}
Disasters and pandemics such as COVID-19 will change the world in many ways and the road to redemption from the ongoing economic distress may require a novel approach. This paper proposes a path towards economic recovery that keeps sustainability at the forefront. A computable general equilibrium model is used to simulate different green tax reform (GTR) policies for triple dividend (TD), consisting of lower emissions, higher GDP and higher employment. The GTR design consists of an energy tax coupled with one of three tax revenue recycle methods: (i) reduction of payroll tax, (ii) reduction of goods and services tax (GST) and (iii) a mixed-recycling approach. The paper also presents the impact of higher productivity on the tax reform simulations, which is a possible positive externality of lower emissions. The study is based on the Australian economy and the salient findings are twofold: (i) productivity gain in the GTR context improves the GDP and employment outcomes in all three different simulation scenarios and (ii) GST reduction has the highest TD potential, followed by reduction of payroll tax.
\end{abstract}

Keywords: green tax reform; CGE modelling; triple dividend; energy tax; positive externality

JEL Classification: $\mathrm{H} 23$; C68; O44; Q48; D62

\section{Introduction}

The use of environmental taxation as a policy instrument to address the negative externalities of economic activities (e.g., pollution) has been growing over the last several decades [1]. One of the key elements of evaluating the performance of such policies, however, is analysing the costs and benefits of the tax-based approach. An extensive literature has stemmed from the double dividend hypothesis [2] that environmental taxation coupled with tax revenue recycling can generate additional economic benefits. When the tax revenue is recycled by reducing other distortionary taxes, such as various consumption or labour taxes, it is referred to as green tax reform (GTR) or environmental tax reform. Here, distortionary taxes refer to taxes based on factors of production such as income, labour, capital etc. Tax on such factors essentially manifests itself as a punishment and therefore discourages capital formation, income generation, productivity and labour. The core premise of the double dividend hypothesis is that such distortionary taxes are harmful to the economy and taxes should be on behaviour that should be discouraged, such as pollution. Tax revenue recycling, on the other hand, refers to the concept of revenue neutrality of environmental tax. This can be achieved through paying back the additional revenue generated from these pollution taxes to the households through a lump sum payment or use the additional revenue to keep the budget unchanged by partially replacing the tax revenues coming from distortionary taxes. 
The efficacy of GTR in yielding double dividend is a well-researched topic, and it is generally accepted that a sensibly designed GTR policy can attain double dividend in the form of lower emissions of greenhouse gasses (GHGs) (primary dividend) with an additional economic benefit that comes from the reduction of distortionary taxes (secondary dividend) [3,4]. However, the impact of the improved environment that comes as a primary dividend of GTR on the additional economic dividend is largely absent in the existing literature. It is worth investigating the interaction between lower emissions and productivity to understand how this may influence the performance of GTR. This is critical because one of the key challenges of widespread acceptance of GTR by policymakers has been the negative outlook that the general public has on the introduction of new taxes [5]. A better and more holistic understanding of how GTR can favourably affect the economy while at the same time reduce emissions can make it more acceptable to the general public.

The COVID-19 pandemic caused global economic distress in 2020 [6]. The underlying consequence is a sharp decline in employment and overall consumption [7]. The current pandemic has also highlighted the negative consequences of economic activities on the environment. The improvement in the quality of environment and the reduction of pollution that has happened in such a short time due to a reduction in human mobility and overall economic production is significant [8]. Such a realisation has led to a push for more sustainable development, and post-COVID-19 fiscal recovery packages are expected to have an emphasis on clean energy and reduction of GHGs [9].

This paper offers a sustainable approach to economic growth, measuring the performance of GTR in a triple dividend (TD) context in Australia. TD is defined as an outcome of GTR that exhibits a cleaner environment (primary dividend), higher consumption (secondary dividend) and improved private welfare in the form of higher employment (tertiary dividend) [10]. In the following sections, this paper often refers to the primary dividend as the environmental dividend and the secondary and tertiary dividends as the economic dividends.

In terms of per capita energy consumption, Australia ranks seventh [11], and higher dependency on fossil fuels is the fundamental reason that Australia is one of the highest in per capita $\mathrm{CO}_{2}$ emissions among the Organization for Economic Co-operation and Development (OECD) countries [12]. Australia is also the only developed country to rescind carbon tax due to the lack of bipartisan support for the policy [13]. According to Copland [14], formulation of climate policies in Australia must include antipolitical sentiments and should be a bottom up approach. These factors make Australia very suitable for our study, which tries to discover additional economic benefits of a carbon pricing mechanism under GTR that can offer greater public and political acceptance.

Lower GHG emissions can reduce the adverse effects that it imposes on the wheat industry [15], the wine industry [16], broadacre crops [17] and livestock systems [18]. A globally orchestrated reduction of GHGs can also improve the frequency and severity of natural disasters such as droughts [19], bushfires [20] and floods [21]. We hypothesise that the reduction of such undesirable effects can lead to greater productivity in agriculture and livestock industries, boosting the TD outcomes of GTR (see Figure 1). We use a computable general equilibrium (CGE) approach to simulate the increase in productivity that comes from GTR and measure its impact on GDP (consumption, secondary dividend) and employment (private welfare, tertiary dividend).

The literature on GTR-driven TD is relatively scant compared to the vast literature available on the double dividend hypothesis. Maxim [22] presents a metaregression analysis based on simulation studies concerning GTR, showing high TD potential under specific GTR designs. In our paper, we design simulations based on these findings to test the performance of GTR in Australia. This makes the paper unique and novel as (i) there is no other simulation study on GTR-driven TD in Australia and (ii) we include productivity gain that comes from improved environment in our simulation design to make the whole scenario more realistic, which is also absent in the existing literature. Our findings can aid policymakers in designing optimal GTR policy instruments that can generate TD. The study is very timely and relevant due to the economic crisis caused by the 2020 COVID-19 pandemic. Therefore, 
the findings of this study can offer greater insight to policymakers in improving the ternary problem of GHGs emissions, recession and higher unemployment.

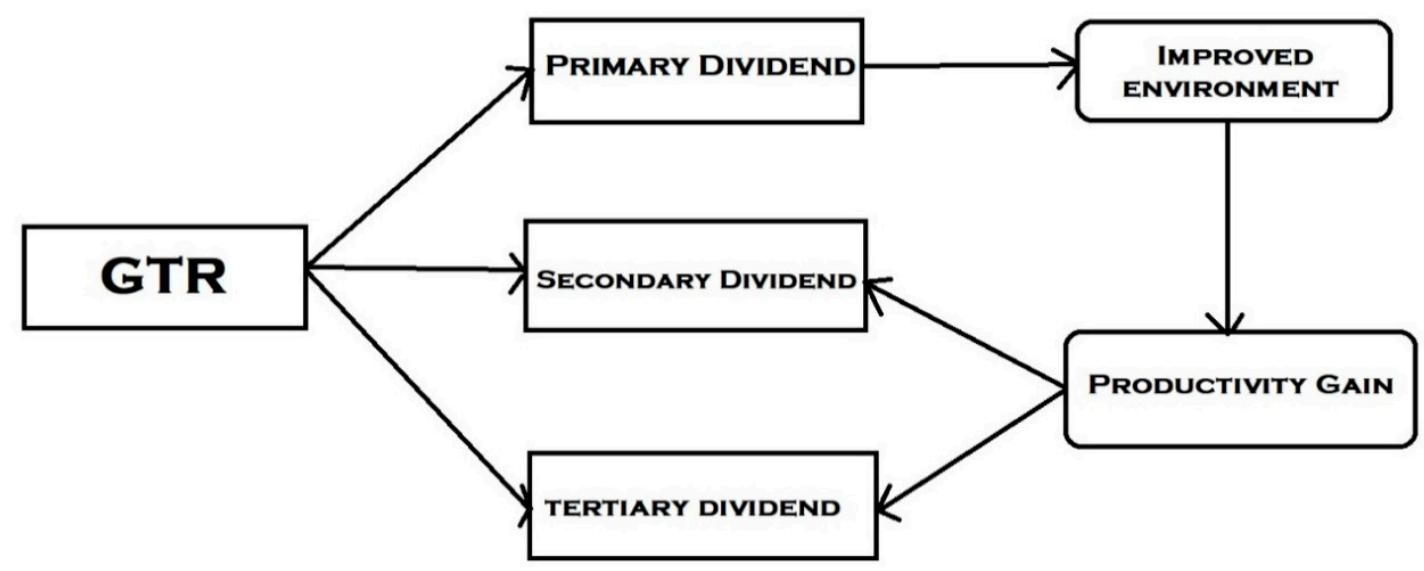

Figure 1. Green tax reform (GTR) driven productivity gain and its impact on triple dividend (TD).

The paper is organised as follows: Section 2 provides a review of the literature concerning TD and GTR simulation studies in Australia; Section 3 provides an overall summary of the model, details of the database and the simulation designs; Section 4 describes the simulation results and Section 5 presents the concluding remarks and policy implications.

\section{Previous Studies}

There is currently no simulation study that holistically covers the TD potential in Australia, and the literature on simulation studies concerning environmental taxation predominantly investigates the environmental dividend and its impact on the whole economy. The earliest studies that simulated the effect of carbon pricing without any tax revenue recycling policy reported how the environmental benefits can come at the cost of lower trade, GDP and employment [23,24]. Further developments in CGE methods led to dynamic studies investigating the effectiveness of carbon pricing through an emissions-trading system, and these reported more promising results see $[25,26]$. The latest studies include Meng, Siriwardana [27], in which the authors found environmental benefits of carbon pricing but with a subtle negative impact on employment and GDP. The effect of carbon tax ranges from a reduction in the output of the brown coal sector [28], a general shrinkage of the tourism industry [29], a rise in electricity prices [30] and a mild to noticeable contraction of the economy [29,31]. The impact of an emissions trading system is examined by Tran, Siriwardana [32], where the authors report strong emissions reduction potential but a $0.3 \%$ reduction in real GDP. The work of Nong [33] presents the economic impact of the current government's policy of allocating 2.55 billion AUD for the Emissions Reduction Fund and how it results in a reduction of real GDP by $0.3 \%$ to $0.4 \%$. Strong evidence for double dividend entailed by carbon taxing in Australia is reported by Fraser and Waschik [34], but there is no existing simulation study that examines the TD potential.

However, the TD of GTR has been investigated through numerous simulation studies in other parts of the world. The metaregression analysis of Maxim [22] presents a synthesis of all simulation studies that measure the effects of GTR on $\mathrm{CO}_{2}$ emissions, employment and GDP. The metaregression shows strong TD potential, predominantly in European countries. Nonetheless, non-European countries also exhibit TD potential when GTR is kept revenue neutral.

The link between pollution, carbon emissions, labour and land productivity in the GTR context is examined in a handful of studies. The nexus between reduced pollution and a rise in overall labour supply is presented by Williams III [35]. The work of Jackson [36] demonstrates how GTR can expedite the innovation of new technology and cost savings, subsequently increasing productivity. Reduction of $\mathrm{CO}_{2}$ emissions can also improve labour productivity [37]. The work of Pradhan and Ghosh [38] 
underscores the adverse consequences on agriculture productivity and how implementation of climate policy to reduce $\mathrm{CO}_{2}$ emissions can minimise that.

The existing literature postulates that there are a myriad of ways that emissions reduction can lead to productivity gain. The literature also contains numerous evidences of GTR-induced TD. However, the gaps that exist include (i) simulation studies that investigate the use of GTR to produce TD in Australia and (ii) use of productivity gain as a positive externality of the primary dividend of GTR and how this can reinforce the secondary and tertiary dividends in a simulation context. Our paper aims to address these gaps and provide a better insight that we believe can provide an environmentally and economically sustainable solution to the post-COVID-19 recession in Australia.

\section{Data and Methods}

\subsection{ORANI-G Model}

The CGE model we use in this study is based on the ORANI-G single-country, multisector comparative static model [39]. ORANI-G has been used extensively in many policy-related decisions made in Australia and several other countries [40-43]. The ORANI model was originally developed for the Australian economy, and ORANI-G is a generic version of this model that embodies all neoclassical assumptions such as cost minimisation, utility maximisation and constant return to scale.

The database used in the model is based on the Australian 2012-2013 input-output (I/O) tables [44] compiled by the Centre of Policy Studies, Australia. The original database has 37 industries and 37 different commodities. One of the key changes we made to the database is that we disaggregated the mining industry into two separate industries: mining_coal and mining_other. In the original database, the mining industry is an aggregation of (i) black coal, (ii) brown coal, (iii) oil, (iv) LNG, (v) gas, (vi) iron ore, (vii) bauxite, (viii) nonferrous metal, (ix) other mining and (x) mining service. We disaggregated black and brown coal from mining and added them to the new industry, mining_coal. The remaining subsectors of the mining industry are found under mining_other. This segregation was influenced by the work of Hardisty, Clark [45], who identified that a noticeable reduction in emissions in Australia is possible just by reducing dependency on coal for energy generation. Therefore, in our study, we add a tax on coal in the form of an energy tax to incorporate this insight.

The core model consists of one government, one investor and one household. Figure A1 in Appendix A illustrates the composition of the database. The behavioural parameters of the agents, such as Armington elasticity, labour elasticity, export demand elasticity etc. are taken from the ORANI-G model [46].

Matrices in the first two rows (V1BAS-V6BAS) demonstrate the flow of commodities from domestic and imported sources to users. It can be translated as a flow of commodity $c$ from domestic or imported sources to a given industry $i$ for production, capital formation, household consumption, export, government consumption and inventories. These direct flows (domestic goods) are measured in basic prices, which are net of the margin cost and sales taxes. For imported goods, basic prices are net of margin costs and sales taxes but also include tariffs.

Matrices in the third row present the flow of domestically produced commodities that are used in margin services, namely wholesale and retail trade, utilities (electric, gas and water), financial services (banking, insurance etc.), transport and hotels.

The fourth row represents the tax paid by a user (V1TAX-V5TAX) for the usage of commodity $c$. V6TAX is excluded because no tax needs to be paid for inventories.

The sixth, seventh and eighth rows present the primary factor inputs, namely labour, fixed capital and agricultural land, which are used by industries to produce the commodities. In our model, labour is categorised into 97 different occupations. V1CAP and V1LND show the rental value of fixed capital and agricultural land.

Rows nine and ten exhibit the other costs and production tax, respectively. Other costs include various production costs, the cost of holding inventories and liquidity cost. 
The remaining two satellite matrices present (i) the multiproduction matrix (MAKE), which presents the basic value of commodity $c$ produced by industry $i$, and (ii) the tariff matrix, which shows the total tariff paid on imported commodity $c$. Table A1 in Appendix A provides a summary of the $\mathrm{I} / \mathrm{O}$ database used in our model. Non-negativity except taxes and inventories, zero pure profit and market clearing are the three most fundamental characteristics of the database.

We implement the productivity gain by controlling the technological change variable. In our model, a1 tot denotes the input-augmenting technical change variable, which is a vector variable with one value for each industry. The relevant equation used in the model is:

$$
x 1 \_s(c, i)-\left[a 1 \_s(c, i)+a 1 \text { tot }(i)\right]=x 1 \text { tot }(i)
$$

where $x 1 \_s(c, i)$ is the intermediate use of imported or domestic composite, $a 1 \_s(c, i)$ is the technological change of intermediate composite (imported or domestic) and $x 1$ tot $(i)$ is the activity level or value added. All these variables are percentage change variables. If the activity level remains constant and we shock $a 1$ tot $(i)$ by $5 \%$, keeping $x 1_{-} s(c, i)$ endogenous and $a 1 \_s(c, i)$ exogenous, then it would mean that $x 1 \_s(c, i)$ would also need to go up by $5 \%$ to keep the equation balanced. Therefore, a positive change in a1tot implies technical regression, whereas a negative change suggests a technical advancement. We use this to calibrate the change of productivity in our model.

We followed the work of De Mooij and Bovenberg [47], who used a 10\% energy tax on energy products in a GTR context, and found it optimal for the employment dividend. We followed their approach and used an energy tax of $10 \%$ in all our simulations. In the original model, interim tax rate on any industry is represented by the variable $t$, which is an endogenous variable and could, therefore, not be shocked directly. We added an exogenous shifter $f t a x \_s i(c)$ with the equation of $t$. The shifter ftax_si $(c)$ denotes uniform percentage changes in the power of tax by commodity and added shocks to energy commodities by controlling the shifter.

Lastly, in all our GTR simulations, we ensured tax revenue neutrality, meaning that all additional tax revenue generated from the energy tax was recycled back into the economy through a reduction of distortionary taxes. This revenue neutrality was ensured through a trial-and-error method. We carefully calibrated the economic shocks to coordinate a tax reform where the amount of added tax revenue and the reduction in tax revenue caused by a decline in different tax is kept equal.

\subsection{Simulation Scenarios}

As mentioned in the previous section, the guidelines for our GTR simulation scenarios are derived from the work on TD by Maxim [22]. The three major findings from that metaregression study that we test in our simulations in an Australian context are (i) a reduction of payroll taxes having the highest TD potential; (ii) a reduction of other taxes, such as food tax, having a noticeable TD potential and (iii) a mixed tax revenue recycling approach using a reduction of multiple distortionary taxes being TD inducive. All these tax revenue recycling schemes are simulated coupled with the energy tax.

For each simulation scenario, we tested three possible productivity gain outcomes: low $(0.25 \%)$, medium $(0.5 \%)$ and high $(1 \%)$. For a more realistic outcome, the productivity gain was limited to the agricultural industry, consisting of wheat, barley, rice, oats, other grain legumes, sugarcane, cotton, fruits and vegetables. Since productivity gain is treated as a positive externality of the primary dividend of GTR, we excluded it from the formation of GTR policy mix. We formed the basic details of the revenue-neutral GTR, such as the energy tax rate, revenue recycle scheme and reduction rate, in the absence of any productivity impact. Instead, we showed how this revenue-neutral GTR policy will perform when different levels of productivity gains are entailed by the reduction of emissions caused by the GTR.

The primary dividend of GTR, which is reduction of $\mathrm{CO}_{2}$ emissions, has already been reported time and again in the literature see $[1,3,4,23,24]$. The nexus between any kind of taxation on the use of fossil fuel, leading to a lower consumption of that and, therefore, lower emissions, is quite 
straightforward and undisputed. The impact of such tax on the economy, however, has been the centre of enquiry. In our study, we took the primary dividend of GTR as a stylised fact and only reported the reduction of the energy product (brown and black coal) instead of incorporating any carbon counting. Our focus of measurement has been the secondary and tertiary dividends in the presence of productivity gain, and this has been reported as percentage differences from the baseline scenario. The baseline scenario measures all the factors in the absence of the GTR policies, and any difference between the baseline scenario and our simulation scenarios describes the changes driven by the GTR.

Simulation 1: In our first simulation, we tested the effect of payroll tax reduction as a form of a tax revenue recycling method in the GTR context. Reduction of payroll tax or any form of labour tax as a tax revenue recycling scheme has been strongly associated with a rise in employment in the short term when used in a GTR scenario see [48]. The underlying reason for this nexus is the substitution between capital and labour. If some degree of substitution is possible between capital and labour, a lower payroll tax makes it cheaper for the producers to substitute capital for labour. Maxim (2020) reports that payroll tax reduction not only has the employment dividend but also has the highest TD potential. From the producers' perspective, a reduction of payroll taxes effectively means a reduction in the wage bill that producers need to pay [49]. In our modified version of the ORANI-G model, no form of labour tax is integrated, and therefore, we used a reduction of real wage as a proxy for a reduction of payroll tax in the first simulation. Revenue neutrality is confirmed by balancing the reduction in the total labour wage bill with the increased tax revenue driven from the energy tax.

Simulation 2: In the second simulation, we incorporated a reduction in goods and sales tax (GST) as the tax revenue recycling method. The effectiveness of food tax reduction was reported in both TD [22] and double dividend [3] situations. The idea was first implemented in a CGE model under the GTR context by Van Heerden, Gerlagh [42], who demonstrated how a reduction in food tax can yield TD in the form of lower emissions, lower poverty and higher GDP. The underlying rationale behind a food tax reduction and economic dividends lies in the influence it has on households. A reduction of the tax on food, which is a necessary consumption, leads to lower household expenditure. This effectively translates to an increase in real wage from the household's perspective. Higher real wage can lead to higher aggregate demand [50] and can, therefore, influence both GDP and employment. Since our study is based on the Australian economy, we incorporate this method by reducing GST on some relatively essential consumptions of the household. As there is no GST on food in Australia, we lowered the GST on (i) clothing and footwear, (ii) textiles, (iii) drinks and smokes, (iv) construction, (v) transport, (vi) rubber and plastic products and (vii) chemicals.

Simulation 3: In our last simulation, we used a mixture of the revenue recycling methods of simulations two and three in a revenue-neutral GTR context to test the TD potential of a mixed-recycling approach.

\subsection{Model Closures}

All three simulations were constructed based on constricted short-term assumptions, keeping capital stock fixed. In addition, in all the simulations, we applied a $10 \%$ tax on brown and black coal. Lastly, we applied the three scenarios of low, medium and high productivity gains to our simulations.

In the first simulation, we applied a uniform $0.185 \%$ payroll tax reduction across all industries and all occupation groups. The GST reduction on seven different commodities in our second simulation is outlined in Table 1.

In our third simulation, we used a mixture of both payroll tax and GST reductions. The payroll tax was reduced by a uniform $0.02 \%$ across all industries. The GST reductions are outlined in Table 2 . 
Table 1. Goods and sales tax (GST) reduction rates.

\begin{tabular}{cc}
\hline Commodity & GST Reduction (\%) \\
\hline Clothing and footwear & 5.0 \\
Textiles & 5.0 \\
Drinks and smokes & 1.0 \\
Construction & 3.0 \\
Transport & 5.0 \\
Chemicals & 3.0 \\
Rubber and plastic products & 4.0 \\
\hline
\end{tabular}

Table 2. GST reduction rates in a mixed tax revenue recycling approach.

\begin{tabular}{cc}
\hline Commodity & GST Reduction (\%) \\
\hline Clothing and footwear & 1.00 \\
Textiles & 1.00 \\
Drinks and smokes & 0.50 \\
Construction & 1.00 \\
Transport & 1.00 \\
Chemicals & 0.50 \\
Rubber and plastic products & 1.00 \\
\hline
\end{tabular}

\section{Results and Discussion}

A standalone policy of energy tax without any revenue recycling is understandably detrimental to the overall economy. Without any presumption of productivity gain, we find that energy tax causes employment to decline by $0.083 \%$ and real GDP to go down by $0.05 \%$, coupled with a $2.6236 \%$ decline in the use of brown and black coal. These numbers are useful for understanding and evaluating the impact of GTR under all our simulation contexts. Table 3 and Figure 2 present the results of a standalone energy tax in three different scenarios of productivity gain.

Table 3. The effects of energy tax on employment, real GDP and coal consumption under different productivity gain scenarios.

\begin{tabular}{cccc}
\hline Policy Scenario & Employment & Real GDP & Consumption of Coal \\
\hline $10 \%$ energy tax with low $(0.25 \%)$ productivity gain & $-0.0744 \%$ & $-0.0357 \%$ & $-2.6202 \%$ \\
\hline $10 \%$ energy tax with medium $(0.5 \%)$ productivity gain & $-0.0658 \%$ & $-0.0224 \%$ & $-2.6169 \%$ \\
\hline $10 \%$ energy tax with high $(1 \%)$ productivity gain & $-0.0488 \%$ & $0.0041 \%$ & $-2.6103 \%$ \\
\hline
\end{tabular}

Our results suggest that even in the absence of any tax revenue recycling, it is possible to partially recover the economic losses of energy tax under the high productivity gain scenario. Nonetheless, TD is unattainable without any form of tax revenue recycling. The results also show a negative relationship between environmental dividends and economic dividends, exhibiting higher environmental benefits coupled with higher economic costs and vice versa, conforming with the findings of Anger, Böhringer [51]. The positive relationship between productivity and GDP that we observe in our results is very sensible. Such an economic growth induced by higher productivity can subsequently create job opportunities and, therefore, lead to higher employment. This positive relationship between productivity and employment in our results is in line with the results of Mahmood [52] in an Australian context. 


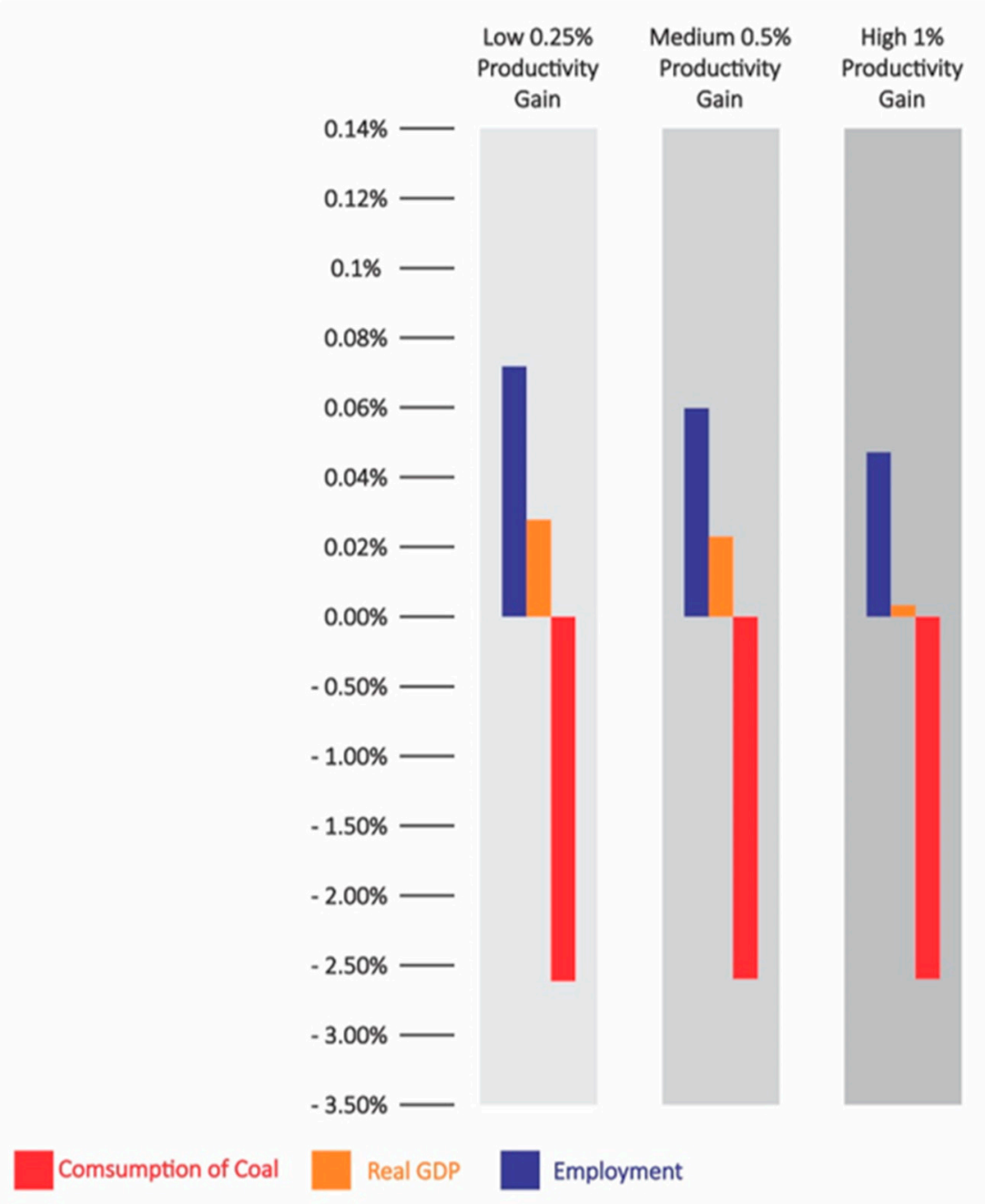

Figure 2. The effects of energy tax on consumption of coal, real GDP and employment under different productivity gain scenarios in the absence of any tax revenue recycle scheme.

Simulation 1: The results of our first simulation exhibit TD potential when GTR is orchestrated with $10 \%$ energy tax and $0.185 \%$ reduction in payroll tax. We observe a high environmental dividend coupled with reasonably weak economic dividends. Our results are in line with those of existing literature on metaregression studies concerning double dividend or TD, supporting the effectiveness of labour tax reduction as a revenue recycling method of GTR $[1,3,4,22]$. The results are presented in Table 4 and Figure 3.

Table 4. The effects of GTR on employment, GDP and coal consumption with payroll tax reduction as the tax revenue recycling method.

\begin{tabular}{|c|c|c|c|}
\hline Policy Scenario & Employment & Real GDP & Consumption of Coal \\
\hline $\begin{array}{l}10 \% \text { energy tax with } 0.185 \% \text { reduction in payroll taxes } \\
\text { [no change in productivity] }\end{array}$ & $0.0341 \%$ & $0.0157 \%$ & $-2.5346 \%$ \\
\hline $\begin{array}{c}10 \% \text { energy tax with } 0.185 \% \text { reduction in payroll taxes } \\
\text { [low productivity gain] }\end{array}$ & $0.0427 \%$ & $0.0290 \%$ & $-2.5312 \%$ \\
\hline $\begin{array}{l}10 \% \text { energy tax with } 0.185 \% \text { reduction in payroll taxes } \\
\text { [medium productivity gain] }\end{array}$ & $0.0513 \%$ & $0.0423 \%$ & $-2.5279 \%$ \\
\hline $\begin{array}{c}10 \% \text { energy tax with } 0.185 \% \text { reduction in payroll taxes } \\
\text { [high productivity gain] }\end{array}$ & $0.0684 \%$ & $0.0690 \%$ & $-2.5214 \%$ \\
\hline
\end{tabular}




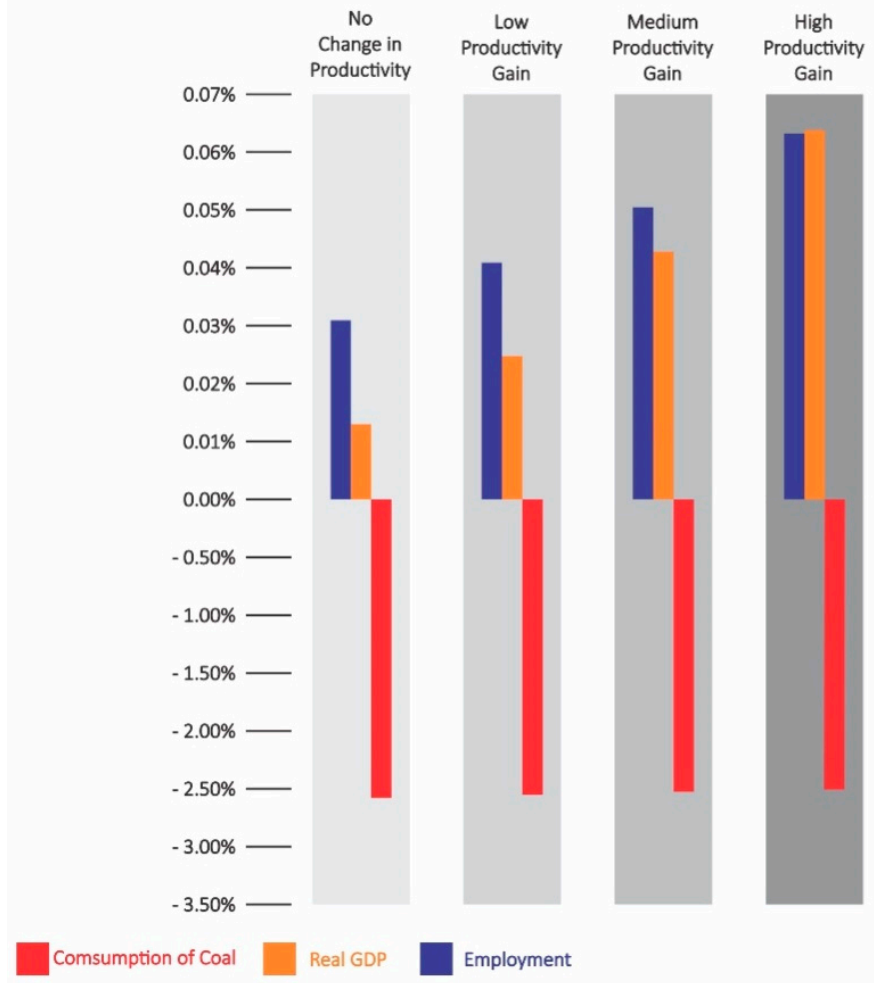

Figure 3. The effects of GTR on consumption of coal, real GDP and employment with payroll tax reduction as the tax revenue recycling method.

Table 5 and Figure 4 show the top six most-affected occupations under this GTR design in the absence of any productivity change. This allowed us to pinpoint the direct impact of the energy tax and reduction of payroll tax on occupations in the short term. The results are perfectly sensible-we observe that occupations in capital-intensive industries are adversely affected due to the energy tax, but that labour-intensive industries gain more employment due to labour becoming cheaper, thanks to the reduction of labour tax.

Table 5. The most affected occupations when tax revenue was recycled through a reduction of payroll tax.

\begin{tabular}{cc}
\hline Occupation & Employment \\
\hline Farmers and farm managers & 0.5636 \\
Food process workers & 0.264 \\
Farm, forestry and garden workers & 0.2803 \\
Stationary plant operators & -0.5219 \\
Building and engineering technicians & -0.0962 \\
Mechanical engineering trades workers & -0.0864 \\
\hline
\end{tabular}

Simulation 2: We find very strong evidence for TD when tax revenue is recycled through a reduction of GST. In particular, the secondary and tertiary dividends of GTR are much stronger under this simulation design. Reduction of GST has not been experimented extensively in CGE simulations on the Australian economy. The effectiveness of GST reduction in creating economic dividends is augmented even further in the presence of different productivity gain scenarios. Our results comply with the findings of Sajeewani, Siriwardana [53], who reported a positive relationship between GST reduction and growth of real GDP in Australia. Our study extends this idea, showing the effectiveness of GST reduction not only in augmenting real GDP but also as having strong potential for generating TD. The results are presented in Table 6 and Figure 5. 


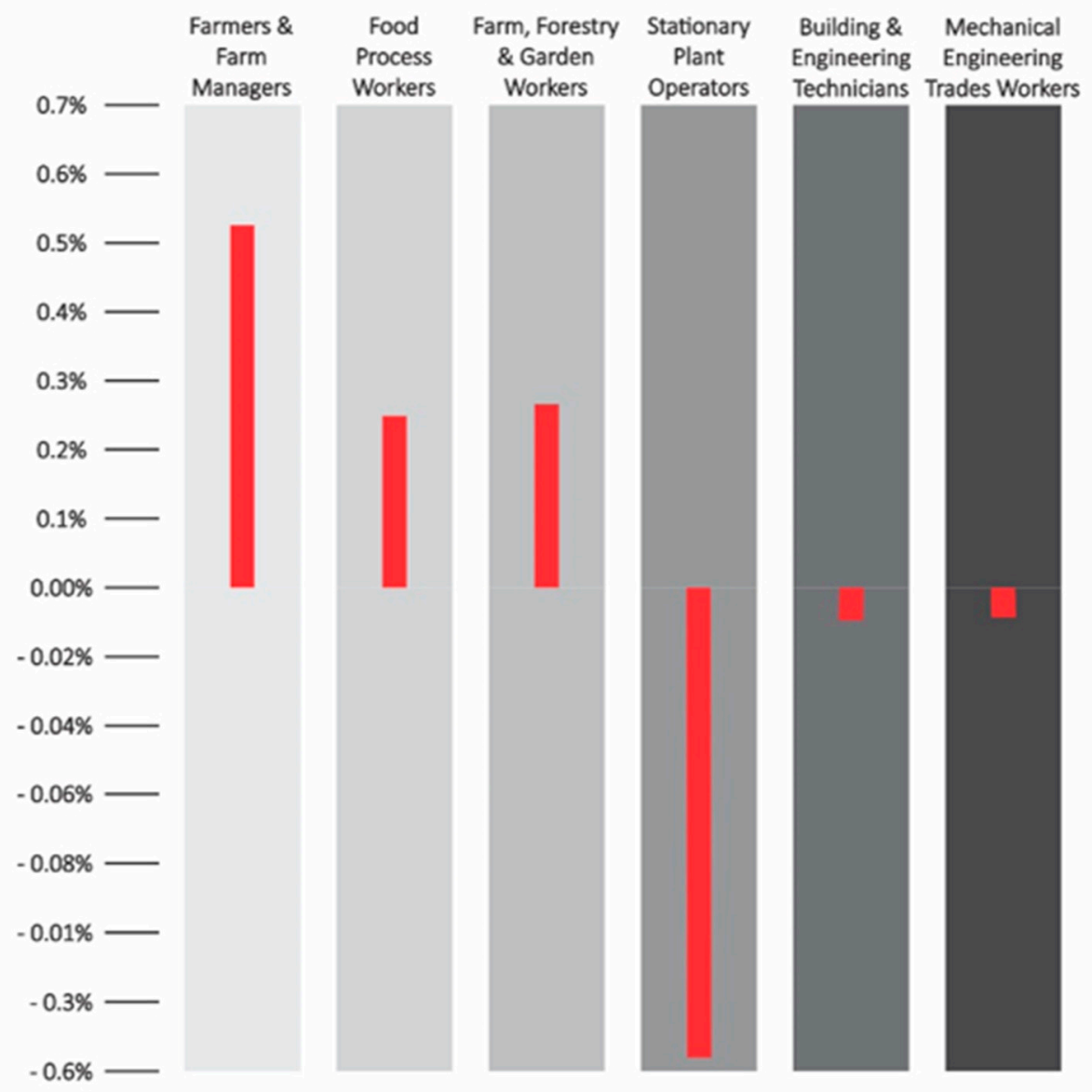

Figure 4. The most affected occupations when tax revenue is recycled through payroll tax reduction.

Table 6. The effects of GTR on employment, GDP and coal consumption with GST reduction as the tax revenue recycling method.

\begin{tabular}{|c|c|c|c|}
\hline Policy Scenario & Employment & Real GDP & Consumption of Coal \\
\hline $\begin{array}{l}10 \% \text { energy tax with various reductions in GST } \\
\text { [no change in productivity] }\end{array}$ & $0.2157 \%$ & $0.1075 \%$ & $-2.3711 \%$ \\
\hline $\begin{array}{c}10 \% \text { energy tax with various reductions in GST } \\
\text { [low productivity gain] }\end{array}$ & $0.2244 \%$ & $0.1209 \%$ & $-2.3678 \%$ \\
\hline $\begin{array}{l}\text { 10\% energy tax with various reductions in GST } \\
\text { [medium productivity gain] }\end{array}$ & $0.2330 \%$ & $0.1343 \%$ & $-2.3645 \%$ \\
\hline $\begin{array}{c}10 \% \text { energy tax with various reductions in GST } \\
\text { [high productivity gain] }\end{array}$ & $0.2502 \%$ & $0.1611 \%$ & $-2.3581 \%$ \\
\hline
\end{tabular}

Simulation 3: In our third simulation, we use the mixed tax revenue recycling approach with $0.02 \%$ payroll tax reduction and the various GST reductions outlined in Table 2 to recycle the tax revenue raised from energy tax. We do not find any TD potential for this revenue-neutral GTR approach. However, weak TD possibilities are observed when measured under various productivity gain scenarios (see Table 7 and Figure 6). Just like all the previous simulation scenarios, we found that productivity gain was positively correlated with the secondary and tertiary dividends, but there was a negative relationship with the environmental dividend. 


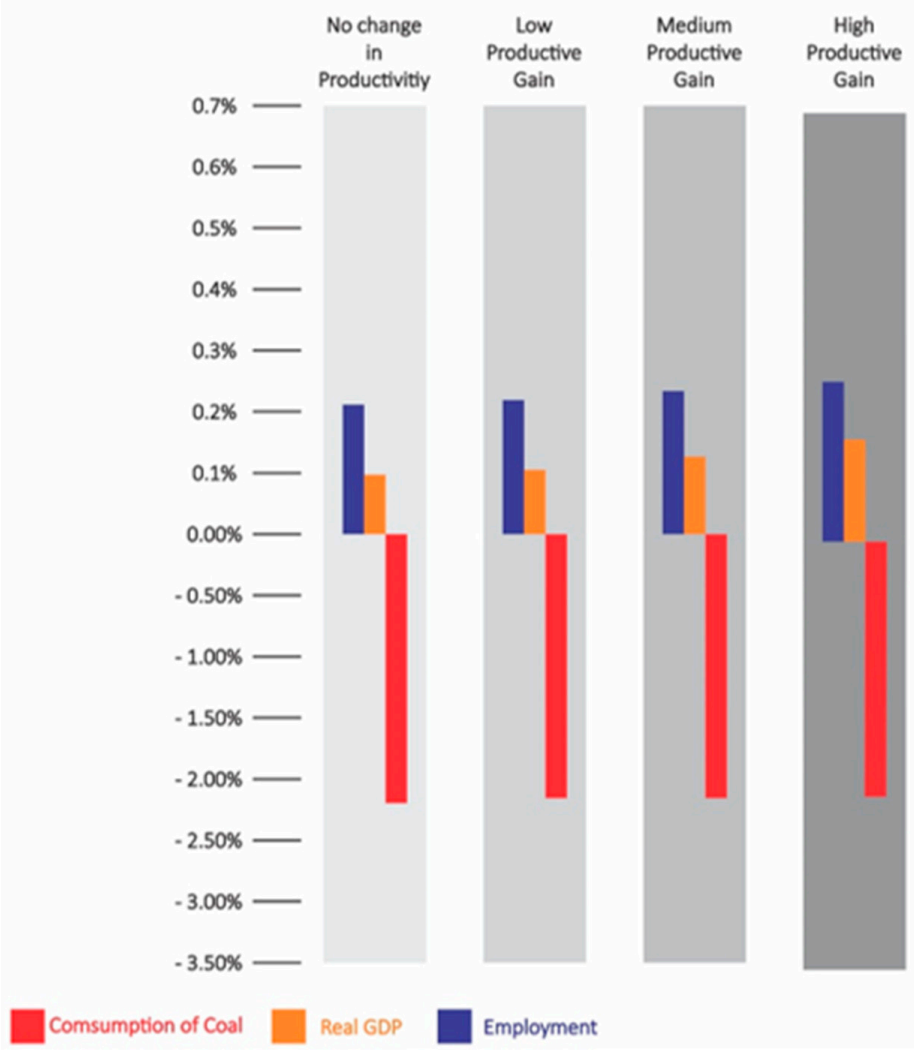

Figure 5. The effects of GTR on coal consumption, real GDP and employment with GST reduction as the tax revenue recycling method.
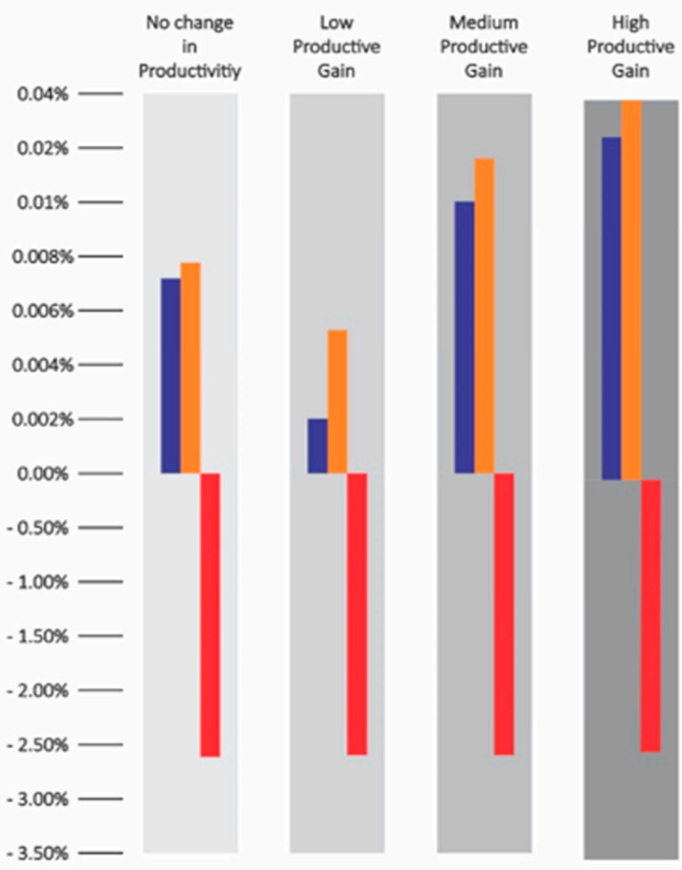

Figure 6. The effects of GTR on consumption of coal, real GDP and employment with mixed tax reduction as the tax revenue recycling method. 
Table 7. The effects of GTR on employment, GDP and coal consumption with a mixed tax revenue recycling approach.

\begin{tabular}{cccc}
\hline Policy Scenario & Employment & Real GDP & Consumption of Coal \\
\hline $\begin{array}{c}10 \% \text { energy tax with 0.02\% reduction in payroll taxes and } \\
\text { various reductions in GST [no change in productivity] }\end{array}$ & $-0.0066 \%$ & $-0.0079 \%$ & $-2.5593 \%$ \\
\hline $\begin{array}{c}10 \% \text { energy tax with 0.02\% reduction in payroll taxes and } \\
\text { various reductions in GST [low productivity gain] }\end{array}$ & $0.0020 \%$ & $0.0055 \%$ & $-2.5559 \%$ \\
\hline $\begin{array}{c}10 \% \text { energy tax with 0.02\% reduction in payroll taxes and } \\
\text { various reductions in GST [medium productivity gain] }\end{array}$ & $0.0106 \%$ & $0.0188 \%$ & $-2.5526 \%$ \\
\hline $\begin{array}{c}10 \% \text { energy tax with 0.02\% reduction in payroll taxes and } \\
\text { various reductions in GST [high productivity gain] }\end{array}$ & $0.0276 \%$ & $0.0454 \%$ & $-2.5461 \%$ \\
\hline
\end{tabular}

\section{Concluding Remarks and Policy Implications}

Our study concludes that a sustainable recovery from the post-COVID-19 recession is possible if GTR is employed, even in the absence of any underlying productivity gain for two revenue recycling approaches, payroll tax reduction and GST reduction. We are not suggesting that this is the fastest way to recovery but addressing one of the common misconceptions that any form of environmental taxation yields environmental benefits at the cost of short-term economic contraction. Rather, we suggest that carefully designed GTR approaches can yield TD outcomes, leading to a more sustainable development. Our study is the first of its kind to examine the effect of productivity gain that can arise as a positive externality of GTR and we conclude that any underlying productivity gain can positively influence the economic dividends in all three simulation approaches. We have found evidence for strong TD under GST reduction and relatively weak TD for payroll tax reduction, and in both cases, TD gets amplified in the presence of productivity gain. However, when the two approaches are combined, the GTR design fails to attain TD, implying a possible interaction between GST and payroll tax. This should be investigated further in future studies. More exploration is also required to quantify the possible productivity gains coming from GTR and emissions reduction. This can be in the form of improved land productivity, technological innovations due to the stringency of environmental taxation and an overall enhanced labour productivity caused by improved environment.

One of the limitations of our study is that we used a static CGE model and therefore unable to quantify the intertemporal effects of GTR. Future researchers should conduct a dynamic study to pinpoint the effects of GTR on TD in the presence of productivity gain in both short and long terms. The other limitation of the study is that we excluded the quantification of emissions reduction and hypothesized it to be a stylised fact. Future studies should include the calculation of emissions reduction to see how our proposed GTR policies can reduce emissions in different industries. A multiregional study can also be conducted to measure the effects of GTR policies in different states and regions.

Despite GST being an effective tool for the government to meet budgetary shortcomings [54], we argue that GST reduction under GTR can be a very effective tool for a sustainable growth plan. GST has been associated with inflation in Australian capital cities [55], and proposing any form of additional taxation to curb emissions can be detrimental to households' welfare, so any political backlash is understandable. Moreover, the regressive nature of carbon pricing in Australia has been reported in numerous studies [56,57], showing that environmental tax imposes more burden on lower-income groups. We propose that a reduction of GST on certain necessary goods and services can alleviate the burden on lower-income groups and address the income distribution problem of any direct or indirect carbon pricing attempt, hence making it politically more acceptable.

In this study, to keep the scenarios practical, we did not apply a drastic change to any existing tax or propose an exorbitant amount of new tax. However, to attain greater TD outcomes more stringent polices can be used that implement the frameworks we propose in this study. This could also lead to a more lasting solution to the emissions problem through technological innovations, consequently paving the way to easier access to alternative energies [58]. 
We hypothesise that the post-COVID-19 era will induce a paradigm change and that there will be political motivation to make sustainable development a higher priority. Our study suggests that the actual economic benefits of GTR are understated when measured in the absence of the positive externality that manifests as improved environment-induced productivity gain. Therefore, future policy decisions concerning GTR should consider this factor to assess the feasibility of such policies.

Author Contributions: M.R.M. designed the research and the simulations, collected the database, made necessary improvements in the model and the database and wrote the original draft. K.K.Z. advised on the analysis and interpretation of data and made comprehensive edits and critical revision of the manuscript. All authors have read and agreed to the published version of the manuscript.

Funding: This paper was conducted as part of a PhD project financially supported by Charles Darwin University in Darwin, Australia.

Conflicts of Interest: The authors declare no conflict of interest.

\section{Appendix A}

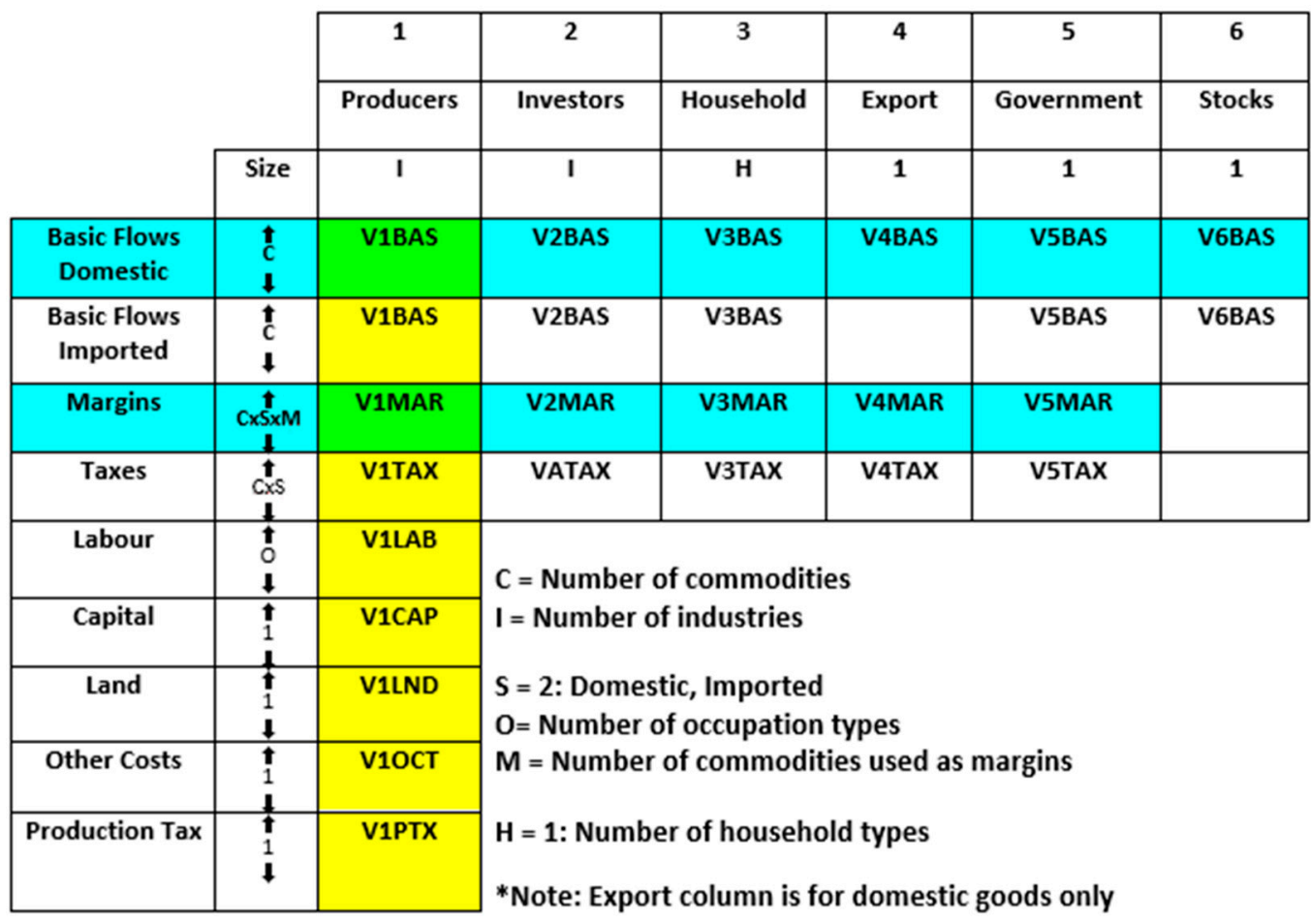

\begin{tabular}{|c|c|c|}
\cline { 2 - 3 } \multicolumn{1}{c|}{} & Make Matrix & \\
\hline Size & I & Total \\
\hline C & MAKE & $\begin{array}{c}\text { sales } \\
\text { row } \\
\text { totals }\end{array}$ \\
\hline Total & =col total absorption & \\
\hline
\end{tabular}

\begin{tabular}{|c|c|}
\cline { 2 - 2 } \multicolumn{1}{c|}{} & Import Duty \\
\hline Size & I \\
\hline C & VOTAR \\
\hline
\end{tabular}

Figure A1. ORANI-G absorption matrix ([46], p. 9). 
Table A1. Contents of the input-output data files ([46], p. 70).

\begin{tabular}{|c|c|c|}
\hline Code & Name & Dimension \\
\hline \multicolumn{3}{|c|}{ 1. Sets } \\
\hline $\mathrm{COM}$ & Set COM commodities & 38 Commodities \\
\hline IND & Set IND industries & 38 Industries \\
\hline SRC & Set SRC sources & 2 Sources \\
\hline MAR & Set MAR margin commodities & 5 Margins \\
\hline OCC & Set OCC occupations & 97 Occupations \\
\hline \multicolumn{3}{|c|}{ 2. Coefficients in the core database } \\
\hline V1BAS & Intermediate basic & $\mathrm{COM}^{*} \mathrm{SRC}^{*} \mathrm{IND}$ \\
\hline V2BAS & Investment basic & $\mathrm{COM}^{*} \mathrm{SRC}^{*} \mathrm{IND}$ \\
\hline V3BAS & Household basic & $\mathrm{COM}^{*} \mathrm{SRC}$ \\
\hline V4BAS & Exports basic & $\mathrm{COM}$ \\
\hline V5BAS & Government basic & $\mathrm{COM}^{*} \mathrm{SRC}$ \\
\hline V6BAS & Inventories basic & $\mathrm{COM}^{*} \mathrm{SRC}$ \\
\hline V1MAR & Intermediate margins & $\mathrm{COM}^{*} \mathrm{SRC}^{*} \mathrm{IND}^{*} \mathrm{MAR}$ \\
\hline V2MAR & Investment margin & $\mathrm{COM}^{*} \mathrm{SRC}^{*} \mathrm{IND}^{*} \mathrm{MAR}$ \\
\hline V3MAR & Household margin & $\mathrm{COM}^{*} \mathrm{SRC}^{*} \mathrm{MAR}$ \\
\hline V4MAR & Export margins & $\mathrm{COM}^{*} \mathrm{MAR}$ \\
\hline V5MAR & Government margins & $\mathrm{COM}^{*} \mathrm{SRC}^{*} \mathrm{MAR}$ \\
\hline V1TAX & Intermediate tax & $\mathrm{COM}^{*} \mathrm{SRC}^{*} \mathrm{IND}$ \\
\hline V2TAX & Investment tax & $\mathrm{COM}^{*} \mathrm{SRC}^{*} \mathrm{IND}$ \\
\hline V3TAX & Household tax & $\mathrm{COM}^{*} \mathrm{SRC}$ \\
\hline V4TAX & Export tax & COM \\
\hline V5TAX & Government tax & $\mathrm{COM}^{*} \mathrm{SRC}$ \\
\hline V1CAP & Capital Rentals & IND \\
\hline V1LAB & Labour & $\mathrm{IND}^{*} \mathrm{OCC}$ \\
\hline V1LND & Land Rentals & IND \\
\hline V1PTX & Production tax & IND \\
\hline V1OCT & Other costs & IND \\
\hline MAKE & Multiproduct matrix & $\mathrm{COM}^{*} \mathrm{IND}$ \\
\hline VOTAR & Tariff revenue & COM \\
\hline
\end{tabular}

\section{References}

1. Maxim, M.R.; Zander, K. Can a Green Tax Reform Entail Employment Double Dividend in European and non-European Countries? A Survey of the Empirical Evidence. Int. J. Energy Econ. Policy 2019, 9, 218-228. [CrossRef]

2. Tullock, G. Excess benefit. Water Resour. Res. 1967, 3, 643-644. [CrossRef]

3. Maxim, M.R.; Zander, K.K.; Patuelli, R. Green Tax Reform and Employment Double Dividend in European and Non-European Countries: A Meta-Regression Assessment. Int. J. Energy Econ. Policy 2019, 9, 342-355. [CrossRef]

4. Patuelli, R.; Nijkamp, P.; Pels, E. Environmental tax reform and the double dividend: A meta-analytical performance assessment. Ecol. Econ. 2005, 55, 564-583. [CrossRef]

5. Dresner, S.; Dunne, L.; Clinch, P.; Beuermann, C. Social and political responses to ecological tax reform in Europe: An introduction to the special issue. Energy Policy 2006, 34, 895-904. [CrossRef]

6. Nicola, M.; Alsafi, Z.; Sohrabi, C.; Kerwan, A.; Al-Jabir, A.; Iosifidis, C.; Agha, M.; Agha, R. The socio-economic implications of the coronavirus and COVID-19 pandemic: A review. Int. J. Surg. 2020. [CrossRef]

7. Baker, S.R.; Farrokhnia, R.A.; Meyer, S.; Pagel, M.; Yannelis, C. How Does Household Spending Respond to an Epidemic? Consumption during the 2020 COVID-19 Pandemic; 0898-2937; National Bureau of Economic Research: Cambridge, MA, USA, 2020.

8. Muhammad, S.; Long, X.; Salman, M. COVID-19 pandemic and environmental pollution: A blessing in disguise? Sci. Total Environ. 2020, 728, 138820. [CrossRef]

9. Hepburn, C.; O'Callaghan, B.; Stern, N.; Stiglitz, J.; Zenghelis, D. Will COVID-19 fiscal recovery packages accelerate or retard progress on climate change? Oxf. Rev. Econ. Policy 2020, 36, 1-48. [CrossRef] 
10. Bovenberg, A.L.; van der Ploeg, F. Optimal taxation, public goods and environmental policy with involuntary unemployment. J. Public Econ. 1996, 62, 59-83. [CrossRef]

11. The World Bank. Energy Use Per Capita-Country Rankings. Available online: https://www.theglobaleconomy. com/rankings/energy_use_per_capita/ (accessed on 23 April 2020).

12. Shahbaz, M.; Bhattacharya, M.; Ahmed, $\mathrm{K} . \mathrm{CO}_{2}$ emissions in Australia: Economic and non-economic drivers in the long-run. Appl. Econ. 2017, 49, 1273-1286. [CrossRef]

13. Taylor, R.; Hoyle, R. Australia Becomes First Developed Nation to Repeal Carbon Tax. 2014. Available online: http://www.wsj.com/articles/australia-repeals-carbon-tax-1405560964 (accessed on 20 April 2020).

14. Copland, S. Anti-politics and Global Climate Inaction: The Case of the Australian Carbon Tax. Crit. Sociol. 2020, 46, 623-641. [CrossRef]

15. Howden, M.; Jones, R.N. Risk assessment of climate change impacts on Australia's wheat industry. In Proceedings of the 4th International Crop Science Congress, Brisbane, Australia, 26 September-1 October 2004.

16. Webb, L.; Whetton, P.; Barlow, E. Climate change and winegrape quality in Australia. Clim. Res. 2008, 36, 99-111. [CrossRef]

17. Anwar, M.R.; Li Liu, D.; Farquharson, R.; Macadam, I.; Abadi, A.; Finlayson, J.; Wang, B.; Ramilan, T. Climate change impacts on phenology and yields of five broadacre crops at four climatologically distinct locations in Australia. Agric. Syst. 2015, 132, 133-144. [CrossRef]

18. Howden, S.; Crimp, S.; Stokes, C. Climate change and Australian livestock systems: Impacts, research and policy issues. Aust. J. Exp. Agric. 2008, 48, 780-788. [CrossRef]

19. Nicholls, N. The changing nature of Australian droughts. Clim. Chang. 2004, 63, 323-336. [CrossRef]

20. Lucas, C.; Hennessy, K.; Mills, G.; Bathols, J. Bushfire Weather in Southeast. Australia: Recent Trends and Projected Climate Change Impacts; Bushfire Cooperative Research Centre, Australian Bureau of Meteorology and CSIRO Marine and Atmospheric Research: Melbourne, Australia, 2007.

21. Whetton, P.; Fowler, A.; Haylock, M.; Pittock, A. Implications of climate change due to the enhanced greenhouse effect on floods and droughts in Australia. Clim. Chang. 1993, 25, 289-317. [CrossRef]

22. Maxim, M.R. Environmental fiscal reform and the possibility of triple dividend in European and non-European countries: Evidence from a meta-regression analysis. Environ. Econ. Policy Stud. 2020, 1-24. [CrossRef]

23. McDougall, R. Short-Run Effects of a Carbon Tax; Centre of Policy Studies (CoPS): Melbourne, UK, 1993.

24. McDougall, R.A. Energy Taxes and Greenhouse Gas. Emissions in Australia; Centre of Policy Studies: Melbourne, Australia, 1993.

25. Adams, P.D. Insurance against catastrophic climate change: How much will an emissions trading scheme cost Australia? Aust. Econ. Rev. 2007, 40, 432-452. [CrossRef]

26. Treasury, A. Strong Growth, Low Pollution: Modelling a Carbon Price; Australian Government: Canberra, Australian, 2011.

27. Meng, S.; Siriwardana, M.; McNeill, J. The Environmental and Economic Impact of the Carbon Tax in Australia. Environ. Resour. Econ. 2013, 54, 313-332. [CrossRef]

28. Meng, X. Will Australian Carbon Tax Affect the Resources Boom? Results from a CGE Model. Nat. Resour. Res. 2012, 21, 495-507. [CrossRef]

29. Dwyer, L.; Forsyth, P.; Spurr, R. Wither Australian tourism? Implications of the carbon tax. J. Hosp. Tour. Manag. 2012, 19, 15-30. [CrossRef]

30. Meng, S. How may a carbon tax transform Australian electricity industry? A CGE analysis. Appl. Econ. 2014, 46, 796-812. [CrossRef]

31. Siriwardana, M.; Meng, S.; McNeill, J. A CGE assessment of the Australian carbon tax policy. Int. J. Glob. Energy Issues 2013, 36, 242-261. [CrossRef]

32. Tran, T.M.; Siriwardana, M.; Meng, S.; Nong, D. Impact of an emissions trading scheme on Australian households: A computable general equilibrium analysis. J. Clean. Prod. 2019, 221, 439-456. [CrossRef]

33. Nong, D. A general equilibrium impact study of the Emissions Reduction Fund in Australia by using a national environmental and economic model. J. Clean. Prod. 2019, 216, 422-434. [CrossRef]

34. Fraser, I.; Waschik, R. The Double Dividend hypothesis in a CGE model: Specific factors and the carbon base. Energy Econ. 2013, 39, 283-295. [CrossRef]

35. Williams, R.C., III. Environmental tax interactions when pollution affects health or productivity. J. Environ. Econ. Manag. 2002, 44, 261-270. [CrossRef] 
36. Jackson, T. The employment and productivity effects of environmental taxation: Additional dividends or added distractions? J. Environ. Plan. Manag. 2000, 43, 389-406. [CrossRef]

37. Lamperti, F.; Dosi, G.; Napoletano, M.; Roventini, A.; Sapio, A. Climate change and green transitions in an agent-based integrated assessment model. Technol. Forecast. Soc. Chang. 2020, 153, 119806. [CrossRef]

38. Pradhan, B.K.; Ghosh, J. Climate policy vs. agricultural productivity shocks in a dynamic computable general equilibrium (CGE) modeling framework: The case of a developing economy. Econ. Model. 2019, 77, 55-69. [CrossRef]

39. Horridge, M.; Parmenter, B.R.; Pearson, K.R. ORANI-G: A General Equilibrium Model. of the Australian Economy; Centre of Policy Studies: Melbourne, Australia, 2000.

40. Kilimani, N.; Heerden, J.V.; Bohlmann, H. Water taxation and the double dividend hypothesis. Water Resour. Econ. 2015, 10, 68-91. [CrossRef]

41. Pui, K.L.; Othman, J. Economics and environmental implications of fuel efficiency improvement in Malaysia: A computable general equilibrium approach. J. Clean. Prod. 2017, 156, 459-469. [CrossRef]

42. Van Heerden, J.; Gerlagh, R.; Blignaut, J.; Horridge, M.; Hess, S.; Mabugu, R.; Mabugu, M. Searching for Triple Dividends in South Africa: Fighting $\mathrm{CO}_{2}$ pollution and poverty while promoting growth. Energy J. 2006, 27, 113-141. [CrossRef]

43. Yusuf, A.A. The Distributional Impact of Environmental Policy: The Case of Carbon Tax and Energy Pricing Reform in Indonesia; Research Report; Environment and Economy Program for Southeast Asia: Singapore, 2008.

44. ABS. Australian National Accounts: Input-Output Tables, 2012-13. Available online: https://www.abs. gov.au/AUSSTATS/abs@.nsf/Lookup/5209.0.55.001Main+Features12012-13?OpenDocument (accessed on 15 February 2020).

45. Hardisty, P.E.; Clark, T.S.; Hynes, R.G. Life cycle greenhouse gas emissions from electricity generation: A comparative analysis of Australian energy sources. Energies 2012, 5, 872-897. [CrossRef]

46. Horridge, M. ORANI-G: A Generic Single-Country Computable General Equilibrium Model; Centre of Policy Studies: Melbourne, Australia, 2003; pp. 9-70.

47. De Mooij, R.A.; Bovenberg, A.L. Environmental taxes, international capital mobility and inefficient tax systems: Tax burden vs. tax shifting. Int. Tax Public Financ. 1998, 5, 7-39. [CrossRef]

48. Bosquet, B. Environmental tax reform: Does it work? A survey of the empirical evidence. Ecol. Econ. 2000, 34, 19-32. [CrossRef]

49. Pisauro, G. The effect of taxes on labour in efficiency wage models. J. Public Econ. 1991, 46, 329-345. [CrossRef]

50. Bhaduri, A.; Marglin, S. Unemployment and the real wage: The economic basis for contesting political ideologies. Camb. J. Econ. 1990, 14, 375-393. [CrossRef]

51. Anger, N.; Böhringer, C.; Löschel, A. Paying the piper and calling the tune?: A meta-regression analysis of the double-dividend hypothesis. Ecol. Econ. 2010, 69, 1495-1502. [CrossRef]

52. Mahmood, M. Labour productivity and employment in Australian manufacturing SMEs. Int. Entrep. Manag. J. 2008, 4, 51-62. [CrossRef]

53. Sajeewani, D.; Siriwardana, M.; Mcneill, J. Household distributional and revenue recycling effects of the carbon price in Australia. Clim. Chang. Econ. 2015, 6, 1550012. [CrossRef]

54. Bolton, T.; Dollery, B. An empirical note on the comparative macroeconomic effects of the GST in Australia, Canada and New Zealand. Econ. Pap. A J. Appl. Econ. Policy 2005, 24, 50-60. [CrossRef]

55. Valadkhani, A.; Layton, A.P. Quantifying the effect of the GST on inflation in Australia's capital cities: An intervention analysis. Aust. Econ. Rev. 2004, 37, 125-138. [CrossRef]

56. Rahman, M.M. The proposed carbon tax in Australia: Impacts on income distribution, employment and competitiveness. In Proceedings of the International Conference on Income Distribution Theory and Policy, Wuhan, China, 15-16 October 2011; pp. 2-13. 
57. Siriwardana, M.; Meng, S.; McNeill, J. The impact of a carbon tax on the Australian economy: Results from a CGE model. In Business, Economics and Public Policy Working Papers 2; University of New England: Armidale, Australia, 2011.

58. Johnstone, N.; Haščič, I.; Poirier, J.; Hemar, M.; Michel, C. Environmental policy stringency and technological innovation: Evidence from survey data and patent counts. Appl. Econ. 2012, 44, 2157-2170. [CrossRef]

(C) 2020 by the authors. Licensee MDPI, Basel, Switzerland. This article is an open access article distributed under the terms and conditions of the Creative Commons Attribution (CC BY) license (http://creativecommons.org/licenses/by/4.0/). 